\title{
Survival probabilities and trends for lip, oral cavity and oropharynx cancers in Northern Portugal in the period 2000-2009
}

\author{
Luís Silva Monteiro', Luís Antunes ${ }^{2}$, Lúcio Lara Santos ${ }^{3,4}$, Maria José Bento ${ }^{2}$ and Saman Warnakulasuriya ${ }^{5}$ \\ 1Department of Medicine and Oral Surgery, Cancer Research Group, IINFACTS, Instituto Universitário de Ciências da Saúde Norte-CESPU, Paredes \\ 4585-116, Portugal \\ ${ }^{2}$ Cancer Epidemiology Group, IPO Porto Research Center (CI-IPOP), Portuguese Oncology Institute of Porto (IPO Porto), Porto 4200-072, Portugal \\ ${ }^{3}$ Experimental Pathology and Therapeutics Group, IPO Porto Research Center (Cl-IPOP), Portuguese Oncology Institute of Porto, Porto 4200-072, Portugal \\ ${ }^{4}$ Department of Surgical Oncology, Portuguese Oncology Institute of Porto, Porto 4200-072 Portugal \\ ${ }^{5}$ King's College London and WHO Collaborating Centre for Oral Cancer, London SE5 9RW, UK
}

Correspondence to: Luís Silva Monteiro. Email: Imonteiro.md@gmail.com

\begin{abstract}
Background: Oral cancer represents a serious public health problem worldwide. Our aim was to analyse the survival probabilities and trends of patients presenting with lip, oral cavity and oropharynx cancers, who were residents in the north of Portugal.

Methods: Using cancer-registry data, we conducted a population-based study of lip, oral cavity and oropharynx cancers diagnosed in the period 2000-2009, among residents in the north of Portugal. Net survival was estimated using the Pohar-Perme estimator. Excess hazard ratios (for gender, age group, tumour location, stage, residence area and period of diagnosis) were estimated using flexible parametric models.

Results: A total of 2,947 cases $(79.5 \%$ males) were included of which $18.5 \%$ were located on the lip, $56.2 \%$ in the oral cavity and $25.3 \%$ in the oropharynx. A large proportion of patients were diagnosed in stages III and IV (18.6\% and $48.7 \%$, respectively). The 5-year net survival (5yr-NS) for all three cancer sites together was $46 \%(95 \% \mathrm{Cl} 44-48)$, being $88 \%(95 \% \mathrm{Cl} 83-94), 41 \%(95 \% \mathrm{Cl} 38-43)$ and $27 \%(95 \% \mathrm{Cl}$ 23-30) for lip, oral cavity and oropharynx cancer, respectively. The 5yr-NS stratified by tumour stage was $84 \%(95 \% \mathrm{Cl} 78-90)$ for stage I, $69 \%(95 \% \mathrm{Cl} 63-76)$ for stage II, $42 \%(95 \% \mathrm{Cl} 37-47)$ for stage III and $19 \%(95 \% \mathrm{Cl} 16-21)$ for stage IV. When comparing the periods 2000-4 and 2005-9, no overall improvements in survival were observed. However, when analysed by stage, a significant reduction in the adjusted excess mortality was observed for stages II $(p=0.021)$ and III $(p<0.001)$.

Conclusion: More than half of the oral cavity and oropharynx cancers were diagnosed in advanced stages of the disease, having a low survival probability. Improvements in survival in the first decade of this century were limited to stages II and III, which were the result of changes in hospital cancer care practices.
\end{abstract}

Keywords: oral cancer, lip cancer, oropharyngeal cancer, net survival, Portugal, trends

Published: 31/07/2018

Received: $14 / 03 / 2018$

ecancer 2018, 12:855 https://doi.org/10.3332/ecancer.2018.855

Copyright: $\odot$ the authors; licensee ecancermedicalscience. This is an Open Access article distributed under the terms of the Creative Commons Attribution License (http://creativecommons.org/licenses/by/3.0), which permits unrestricted use, distribution, and reproduction in any medium, provided the original work is properly cited. 


\section{Background}

Lip, oral cavity and pharynx cancers were in 2012 the sixth most common cancers in Europe for men [Age-standardised rate (ASR): 18.2/100,000] while for women they ranked in the 16th place (ASR: 4.9/100,000) (EUCAN) [1]. A total of 43,704 deaths due to this disease were estimated to have occurred during 2012 in Europe being almost $80 \%$ in men [1]. The incidence and mortality rates of lip, oral cavity and pharynx cancers vary widely between European countries and regions of Europe [2, 3]. Hungary was the country with the highest incidence rate (ASR: 23.3/100,000) contrasting with other countries such as Cyprus with a low incidence rate (ASR: 2.7/100,000 habitants) for these tumours [1]. Contrary to other southern European countries, Portugal presents a relatively high incidence rate of these tumours ranking in fourth place in Europe (considering both sexes) and second place in Southern Europe. A total of 2,082 new cases were estimated for the year 2012 (ASR: 15.4/100,000) [1]. Also, an increasing trend in oral cancer was reported since the beginning of the new century in Portugal [2]. This trend was observed in both sexes but it was more evident in females [2]. In terms of mortality, Portugal ranks better (13th) with an estimated mortality rate of 5.5/100,000 [1]. Nevertheless, more than half of the cases in our country are diagnosed in advanced stages, in particular in the north of Portugal and over two-thirds have regional metastasis at diagnosis [4,5] contributing to low survival from this type of tumours.

The most common histological type of oral cancer is squamous cell carcinoma and [2] tobacco and alcohol consumption constitute the major risk factors for oral cavity cancers and exposure to sunlight for lip cancers [6]. Additionally, human papilloma virus (HPV) infection has been recognised as an important cause, especially for oropharyngeal cancers [6].

In the first decade of this century, there have been some changes in the clinical practice in the northern region of Portugal regarding head and neck tumours according to European Society for Medical Oncology recommendations [7]. Population-based cancer survival analysis is the best way to evaluate the impact of these changes on outcomes. The aim of the present study was thus to analyse the patterns in net survival from lip, oral cavity and oropharyngeal cancers using a population-based dataset of cancer patients diagnosed in the north of Portugal during the period 2000-2009, in order to understand the impact of these changes.

\section{Methods}

Information was extracted from the population-based North Region Cancer Registry of Portugal (RORENO). We considered eligible for analysis all new lip, oral cavity and oropharynx malignant epithelial neoplasms, diagnosed between 1 January 2000 and 31 December 2009 , occurring in men and women aged 15 or more and resident in the north of Portugal (including the districts of Braga, Bragança, Porto, Viana do Castelo and Vila Real). We divided the study into two 5 year periods (2000-4 and 2005-9) in order to evaluate possible improvements in survival during this decade. We reclassified all cases according to the 10th revision of the International Classification of Diseases [8]. For the analysis, tumour locations were categorised into three groups: lip (C00), oral cavity (tongue: C01-02, gum: C03, floor of the mouth: C04 and palate and other unspecified parts of the mouth: C05-06) and oropharynx (tonsil: C09, oropharynx: C10 and other ill-defined sites: C14). Malignant neoplasms of major salivary glands (C07-08), nasopharynx and hypopharynx (C11-13) were not considered in this analysis. Tumour stage was reclassified according to the 7th edition of the classification of malignant tumours of American Joint Committee on Cancer [9]. The follow-up of the vital status of each patient was updated until 31 July 2015, using the National Health Service database.

The area of residence (parish) at diagnosis for each patient was classified as rural, moderately urban or urban according to the classification defined by the Statistics Office of Portugal [10].

The association between categorical variables was evaluated using the Chi-square test or Fisher test whenever applicable. Survival time was defined as the time between tumour diagnosis and patient's death from any cause, end of the study period or date lost to follow-up, whichever occurred first. Net survival from cancer was estimated using the Pohar-Perme net survival estimator [11]. Net survival is a hypothetical quantity that represents the probability of survival in the absence of other causes of death. For the population background mortality, we used the life tables built in the framework of the CONCORD-2 study (http://csg.Ishtm.ac.uk/tools-analysis/ life-tables/) stratified by sex, age and calendar year. Excess hazard ratios (EHRs) were computed using flexible parametric models [12]. Univariable models were used to assess the prognosis value of each studied variable. A multivariable model was built with all the variables analysed (age group, sex, topography, stage of disease at diagnosis, a period of diagnosis and typology of residence area) 
but keeping only the significant variables in the final model. Furthermore, to evaluate improvements in survival by the stage of disease, we built different models for each level of this variable. Since we had less than $30 \%$ of cases with missing information on stage, we used multiple imputation techniques in the analysis. Variables in the imputation model included all of the variables considered in the substantive model referred above plus vital status, survival time and the Nelson-Aalen estimate of the cumulative hazard as proposed by Falcaro et al [13]. EHRs were estimated using Rubin rules. All calculations were performed using STATA software. Results were considered statistically significant for $p$-value $<0.05$.

\section{Results}

A total of 2,947 cases with lip, oral cavity or oropharynx cancer were reported in the study period. The characteristics of the cohort of patients analysed are presented in Table 1. The male-to-female ratio was 3.9:1. The location most commonly affected was the tongue (823; $27.9 \%)$, followed by tonsils and oropharynx (630; $21.4 \%)$, lip (544; 18.5\%), buccal mucosa $(311 ; 10.6 \%)$, floor of the mouth $(237 ; 8.0 \%)$, palate $(160 ; 5.4 \%)$, gums $(125 ; 4.2 \%)$ and pharynx $(117 ; 4 \%)$. Squamous cell carcinomas corresponded to $92.5 \%(n=2,752)$ of all tumours.

Table 1. The description of the cohort of patients analysed.

\begin{tabular}{|c|c|c|c|c|c|c|c|c|}
\hline \multirow[t]{2}{*}{ Variable } & \multicolumn{2}{|c|}{ All sites } & \multicolumn{2}{|c|}{ Lip } & \multicolumn{2}{|c|}{ Oral cavity } & \multicolumn{2}{|c|}{ Oropharynx } \\
\hline & $N$ & $\%$ & $n$ & $\%$ & $N$ & $\%$ & $n$ & $\%$ \\
\hline Total & 2947 & 100 & 544 & 100 & 1656 & 100 & 747 & 100 \\
\hline \multicolumn{9}{|l|}{ Gender } \\
\hline Male & 2342 & 79.5 & 358 & 65.8 & 1286 & 77.7 & 698 & 93.4 \\
\hline Female & 605 & 20.5 & 186 & 34.2 & 370 & 22.3 & 49 & 6.6 \\
\hline \multicolumn{9}{|l|}{ Age group } \\
\hline $15-44$ & 357 & 12.1 & 34 & 6.3 & 216 & 13.0 & 107 & 14.3 \\
\hline $45-54$ & 712 & 24.2 & 38 & 7.0 & 413 & 24.9 & 261 & 34.9 \\
\hline $55-64$ & 725 & 24.6 & 87 & 16.0 & 419 & 25.3 & 219 & 29.3 \\
\hline $65-74$ & 619 & 21.0 & 158 & 29.0 & 348 & 21.0 & 113 & 15.1 \\
\hline $75+$ & 534 & 18.1 & 227 & 41.7 & 260 & 15.7 & 47 & 6.3 \\
\hline \multicolumn{9}{|c|}{ Stage at diagnosis* } \\
\hline I & 398 & 18.6 & 195 & 69.6 & 187 & 14.1 & 16 & 3.0 \\
\hline II & 302 & 14.1 & 50 & 17.9 & 200 & 15.1 & 52 & 9.7 \\
\hline III & 399 & 18.6 & 18 & 6.4 & 256 & 19.3 & 125 & 23.3 \\
\hline IV & 1044 & 48.7 & 17 & 6.1 & 683 & 51.5 & 344 & 64.1 \\
\hline Unknown & 804 & & 264 & & 330 & & 210 & \\
\hline \multicolumn{9}{|c|}{ Typology of residence area* } \\
\hline Rural & 325 & 11.1 & 108 & 20.0 & 284 & 17.2 & 128 & 17.2 \\
\hline Medium urban & 520 & 17.7 & 103 & 19.0 & 162 & 9.8 & 60 & 8.0 \\
\hline Urban & 2096 & 71.3 & 330 & 61.0 & 1208 & 73.0 & 558 & 74.8 \\
\hline Unknown & 6 & & 3 & & 2 & & 1 & \\
\hline \multicolumn{9}{|c|}{ Period of diagnosis } \\
\hline 2000-2004 & 1275 & 43.3 & 288 & 52.9 & 691 & 41.7 & 296 & 39.6 \\
\hline 2005-2009 & 1672 & 56.7 & 256 & 47.1 & 965 & 58.3 & 451 & 60.4 \\
\hline
\end{tabular}

*percentage within cases with information 
For oral cavity and oropharynx cancers, more than half of the patients were diagnosed in stage IV ( $51.5 \%$ and $64.1 \%)$, while for lip cancer the most frequent was stage I (69.6\%).

Most of the patients were resident in urban areas (71.3\%). The proportion of lip cancer patients coming from rural or medium urban areas was significantly higher than this proportion for the two other cancer types $(P<0.001)$.

Five-year net survival (5yr-NS) for all cases is presented in Table 2 (and Figure 1). For all cancers, the 5yr-NS probability was $45.8 \%$ $(95 \% \mathrm{Cl} 43.7-47.8)$. Women presented a better survival than men for all cancer sites. Net survival did not vary by age group, although a slightly better 5yr-NS was observed for the older patients for oral cavity and oropharynx cancers. As expected, the 5yr-NS decreased with increasing stage, ranging from $84 \%$ (stage I) to $19 \%$ (stage IV) when considering all tumours. No major differences in survival were observed by the typology of residence, although patients living in rural areas had a slightly better survival.

Lip tumours had the best prognosis, followed by oral cavity cancer and then oropharynx (Table 2, Figure 1).

Table 2. Net survival at 5 years of follow-up by tumour site.

\begin{tabular}{|c|c|c|c|c|c|c|c|c|}
\hline \multirow{3}{*}{ Variable } & \multicolumn{8}{|c|}{ 5yr-NS } \\
\hline & \multicolumn{2}{|c|}{ All sites } & \multicolumn{2}{|c|}{ Lip } & \multicolumn{2}{|c|}{ Oral cavity } & \multicolumn{2}{|c|}{ Oropharynx } \\
\hline & $\%$ & $95 \% \mathrm{Cl}$ & $\%$ & $95 \% \mathrm{Cl}$ & $\%$ & $95 \% \mathrm{Cl}$ & $\%$ & $95 \% \mathrm{Cl}$ \\
\hline All & 46 & $44-48$ & 88 & 83-94 & 41 & $38-43$ & 27 & $23-30$ \\
\hline \multicolumn{9}{|l|}{ Gender } \\
\hline Male & 41 & $39-43$ & 86 & $80-93$ & 37 & $33-39$ & 26 & $23-29$ \\
\hline Female & 64 & $59-69$ & 89 & $80-98$ & 54 & $48-60$ & 34 & $20-48$ \\
\hline \multicolumn{9}{|l|}{ Age group } \\
\hline $15-44$ & 42 & $37-47$ & 94 & $86-100$ & 42 & $36-49$ & 25 & $16-33$ \\
\hline $45-54$ & 36 & $33-40$ & 91 & $82-100$ & 38 & $33-42$ & 26 & $21-31$ \\
\hline $55-64$ & 43 & $39-47$ & 89 & $81-97$ & 42 & $37-47$ & 25 & $19-31$ \\
\hline $65-74$ & 50 & $45-54$ & 89 & $82-97$ & 39 & $33-44$ & 28 & $19-37$ \\
\hline $75+$ & 60 & $53-67$ & 85 & $73-96$ & 43 & $34-51$ & 35 & $18-53$ \\
\hline \multicolumn{9}{|l|}{ Stage at diagnosis } \\
\hline 1 & 84 & $78-90$ & 93 & $84-100$ & 76 & $68-84$ & 66 & $41-92$ \\
\hline II & 69 & $63-76$ & 87 & $71-100$ & 68 & $60-76$ & 55 & $40-70$ \\
\hline III & 42 & $37-47$ & 60 & $31-89$ & 44 & $37-51$ & 34 & $25-43$ \\
\hline IV & 19 & $16-21$ & 26 & $0-54$ & 20 & $17-23$ & 16 & $12-20$ \\
\hline \multicolumn{9}{|c|}{ Typology of residence area } \\
\hline Predominantly rural & 52 & $46-59$ & 95 & 84-100 & 36 & $28-44$ & 24 & $12-35$ \\
\hline Medium urban & 45 & $40-50$ & 87 & $74-100$ & 39 & $33-45$ & 24 & $17-32$ \\
\hline Predominantly urban & 45 & $42-47$ & 86 & $78-92$ & 41 & $38-44$ & 27 & $23-31$ \\
\hline \multicolumn{9}{|l|}{ Period of diagnosis } \\
\hline 2000-2004 & 46 & $42-49$ & 85 & $78-93$ & 38 & $34-42$ & 24 & $18-29$ \\
\hline 2005-2009 & 46 & $43-49$ & 91 & 83-99 & 41 & 39-45 & 28 & $24-33$ \\
\hline
\end{tabular}



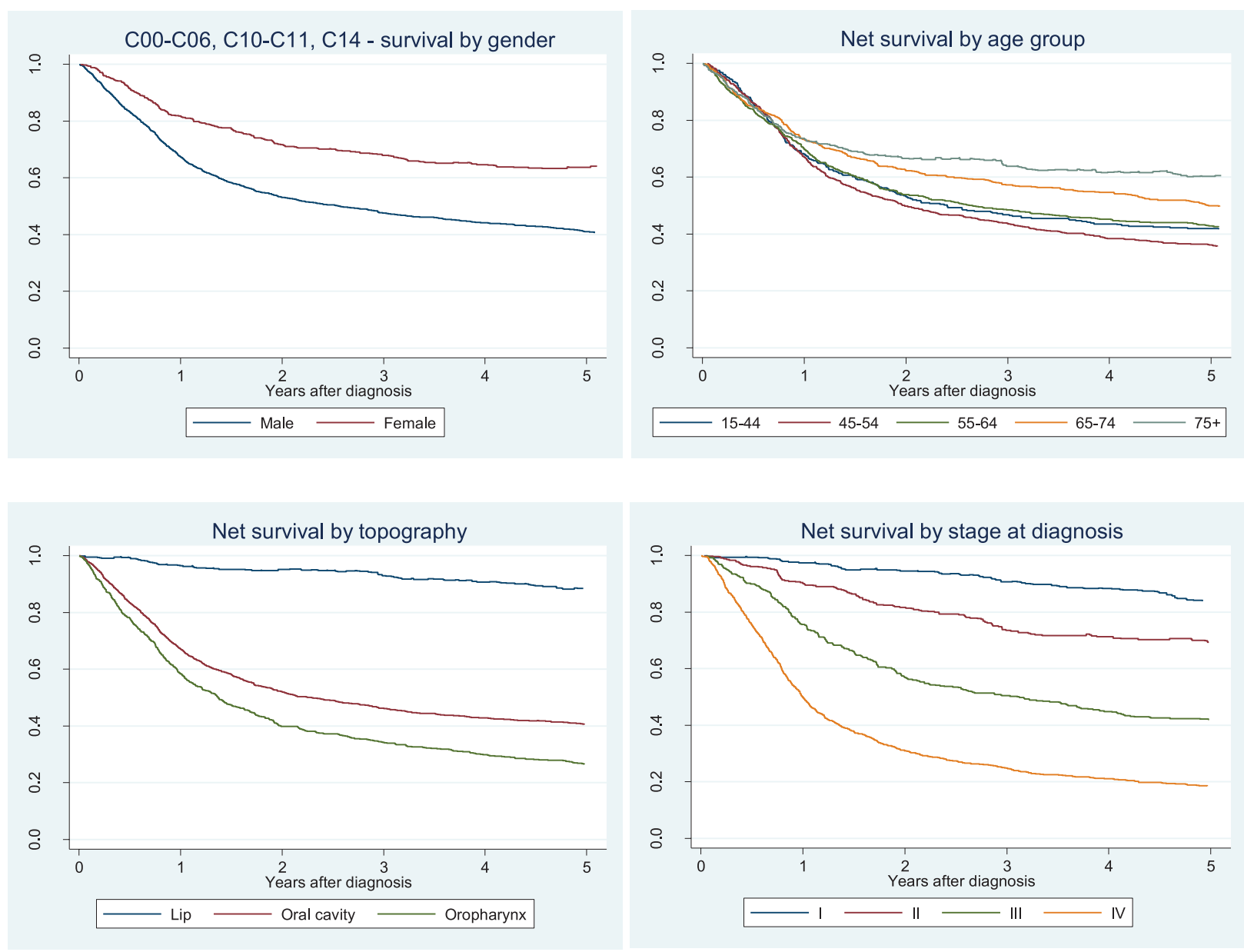

Figure 1. Net survival by gender, age location and clinical stage.

Considering all sites together, we observed that the 5yr-NS did not change between the two time periods (45.6\% versus $45.8 \%)$. Stratifying by tumour site, we observed a slight increase in 5yr-NS in the later period for each of three locations considered (Table 3). We observed an increase in 5yr-NS only in stages II and III (Figure 2).

Female patients had a decreased adjusted excess hazard $(E H R=0.76 ; 95 \% \mathrm{Cl}: 0.63-0.91)$ and only patients with 65 or plus years of age had an increased excess mortality $(65-74: \mathrm{EHR}=1.30,95 \% \mathrm{Cl}: 1.04-1.63$ and $75+$ : $\mathrm{EHR}=1.34,95 \% \mathrm{Cl}: 1.02-1.76)$. Patients with oropharyngeal cancers had an increased excess hazard relative to oral cavity cancer patients $(\mathrm{EHR}=1.20 ; 95 \% \mathrm{Cl}$ : $1.06-1.36)$ while lip cancers had almost $70 \%$ less excess hazard (EHR $=0.32 ; 95 \% \mathrm{Cl}: 0.20-0.52)$. Stages II-IV presented an increased excess mortality when compared to stage I tumours (Table 4). The patients diagnosed in the most recent period (2006-9) presented a decreased excess mortality (16\%) compared to patients diagnosed in 2000-4. A significant reduction in excess mortality (40\%) was observed for stages II and III but not for stages I and IV (Table 5). 
Table 3. Net survival at 5 years of follow-up by a period of diagnosis.

\begin{tabular}{|c|c|c|c|c|}
\hline \multirow{3}{*}{ Variable } & \multicolumn{4}{|c|}{$5 y r-N S$} \\
\hline & \multicolumn{2}{|c|}{ Period 2000-2004 } & \multicolumn{2}{|c|}{ Period 2005-2009 } \\
\hline & $\%$ & $95 \% \mathrm{Cl}$ & $\%$ & $95 \% \mathrm{Cl}$ \\
\hline All & 46 & $42-49$ & 46 & $43-49$ \\
\hline \multicolumn{5}{|l|}{ Gender } \\
\hline Male & 41 & $37-44$ & 42 & $38-44$ \\
\hline Female & 66 & $59-74$ & 62 & $56-68$ \\
\hline \multicolumn{5}{|l|}{ Age group } \\
\hline $15-44$ & 43 & $35-51$ & 41 & $35-48$ \\
\hline $45-54$ & 35 & $29-40$ & 37 & $33-42$ \\
\hline $55-64$ & 46 & $40-51$ & 41 & $36-46$ \\
\hline $65-74$ & 48 & $41-54$ & 52 & $46-58$ \\
\hline $75+$ & 57 & $47-67$ & 63 & $54-72$ \\
\hline \multicolumn{5}{|l|}{ Topography } \\
\hline Lip & 85 & $78-93$ & 91 & $83-100$ \\
\hline Oral cavity & 38 & $34-42$ & 42 & $39-45$ \\
\hline Oropharynx & 24 & $19-29$ & 28 & $24-33$ \\
\hline \multicolumn{5}{|l|}{ Stage at diagnosis } \\
\hline 1 & 85 & $77-94$ & 82 & 73-91 \\
\hline II & 62 & $53-72$ & 76 & $67-84$ \\
\hline III & 32 & $25-40$ & 47 & $40-54$ \\
\hline IV & 18 & $14-22$ & 19 & $16-22$ \\
\hline \multicolumn{5}{|c|}{ Typology of residence area } \\
\hline Predominantly urban & 43 & $40-47$ & 46 & $43-49$ \\
\hline Medium urban & 54 & $46-62$ & 40 & $34-46$ \\
\hline Predominantly rural & 48 & $39-58$ & 55 & $46-64$ \\
\hline
\end{tabular}

\section{Discussion}

In this population-based study, we aimed to analyse the survival probabilities and trends of patients with lip, oral cavity and oropharynx cancers among residents in the north of Portugal in the first decade of this century. A low survival probability was confirmed for oral cavity and oropharynx tumours, contrasting with lip cancers that presented a higher survival. For oral cavity and oropharynx cancers, our results are lower than the survival figures observed in many world regions, in particular the European region where survival rates for oral cavity are between $45 \%$ and $50 \%$ and oropharynx cancers close to $41 \%[3,14]$ while in our region it was $41 \%$ and $27 \%$, respectively. Surveillance, Epidemiology, and End Results (SEER) data for the United States in 2009 revealed a $5 y$ rs-NS of $67.2 \%$ for oral cavity and pharynx cancers [15].

Lip cancer presented a high survival rate when compared to the other sites studied, similarly to what has been observed in other studies $[14,16,17]$. 

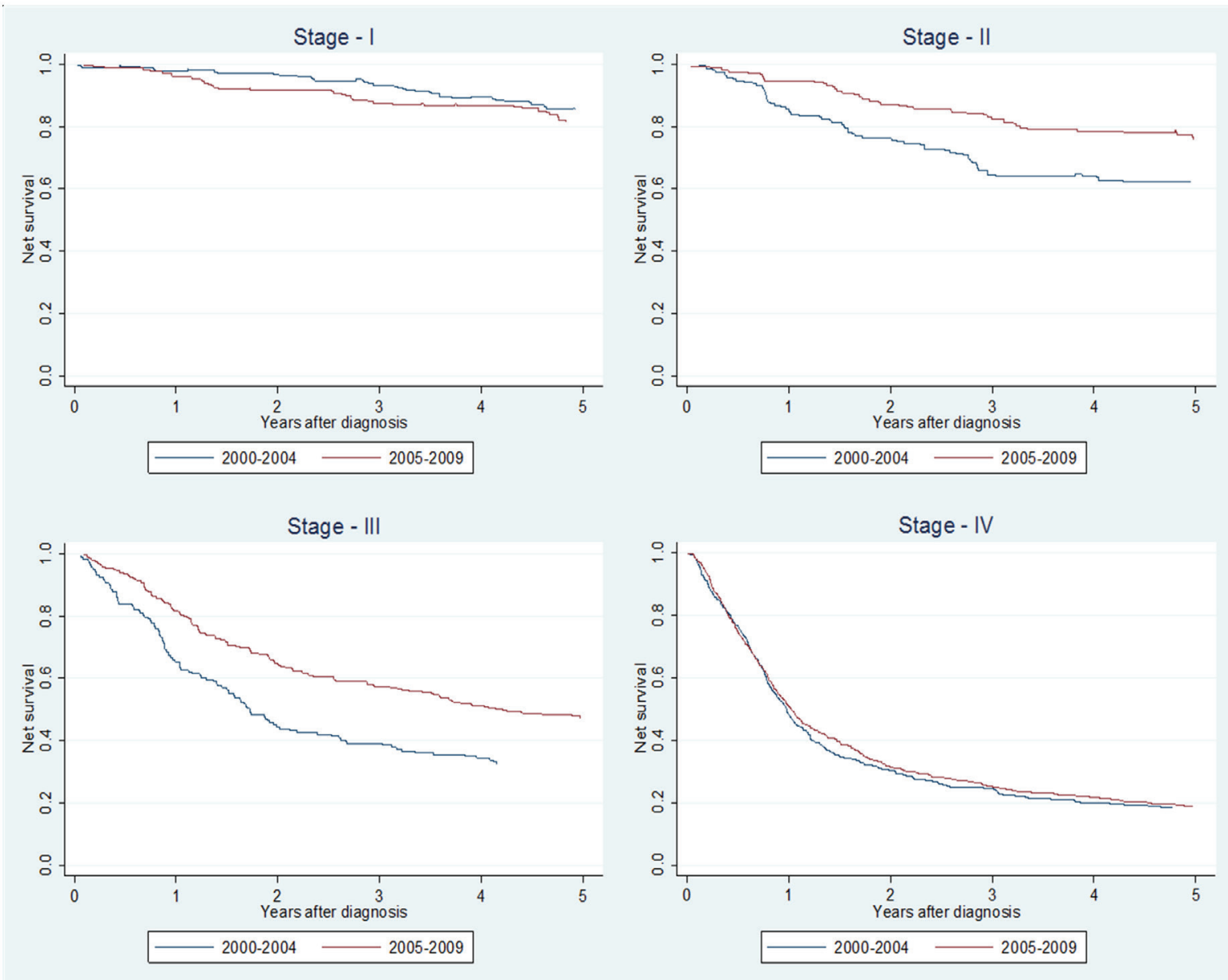

Figure 2. Net survival for the periods 2000-2004 and 2005-2009 analysed by clinical stage (AJCC 7th ed).

Significant reductions of excess mortality in the most recent period for oral cavity and oropharynx tumours diagnosed in stage II or III were observed. These observed improvements occurred in the period in which a coordinated multidisciplinary treatment approach, the creation of a surgical and pathological dedicated team, took place in most of the hospitals in the North region of Portugal. We also followed a clear definition of neck dissection (selective or modified radical) depending on the clinical stage and tumour thickness. More effective chemotherapy adjuvant protocols (cisplatin, 5-Fu and taxanes) combined with high-quality radiotherapy were applied. This fact reduced the risk of side effects that associated with nutritional support allowed a better adherence to the treatment protocols. High-quality follow-up tailored by the risk of cancer recurrence was also implemented in this period [18].

However, no survival improvements were observed for early diagnosed tumours (stage I). Probably this fact stems from the treatment performed being standardised and additional improvements being difficult to achieve.

No survival improvements were observed for advanced tumours (stage IV) either. This could reflect the fact that patients with advanced disease have mainly no capacity for supporting systemic treatment including the new types of treatments and new chemo-radiotherapy approaches [19]. It is expected that with the introduction of targeted cancer therapies, immunological oncology approaches for head and neck cancer therapy and photodynamic therapy, survival from more advanced cancers can be improved [20]. Since these types of treatments are more recent, the patients included in our cohort could not benefit from them. 
Table 4. Non-adjusted and adjusted EHRs.

\begin{tabular}{|c|c|c|c|c|}
\hline \multirow{2}{*}{ Variable } & \multicolumn{2}{|c|}{ Non-adjusted } & \multicolumn{2}{|c|}{ Adjusted } \\
\hline & $\mathrm{EHR}^{\mathrm{a}}$ & $95 \% \mathrm{Cl}$ & $\mathrm{EHR}^{\mathrm{a}}$ & $95 \% \mathrm{Cl}$ \\
\hline \multicolumn{5}{|l|}{ Gender } \\
\hline Male & 1 & & 1 & \\
\hline Female & 0.48 & $0.41-0.57$ & 0.69 & $0.58-0.82$ \\
\hline \multicolumn{5}{|l|}{ Age group } \\
\hline $15-44$ & 1 & & 1 & \\
\hline $45-54$ & 1.16 & $0.99-1.36$ & 0.98 & $0.83-1.16$ \\
\hline $55-64$ & 1.01 & $0.85-1.19$ & 1.07 & $0.90-1.27$ \\
\hline $65-74$ & 0.81 & $0.67-0.97$ & 1.14 & 0.95-1.38 \\
\hline $75+$ & 0.62 & $0.50-0.77$ & 1.41 & $1.13-1.76$ \\
\hline \multicolumn{5}{|l|}{ Topography } \\
\hline Oral cavity & & & 1 & \\
\hline Lip & 0.09 & $0.05-0.14$ & 0.27 & $0.18-0.42$ \\
\hline Oropharynx & 1.44 & $1.29-1.60$ & 1.15 & $1.03-1.29$ \\
\hline \multicolumn{5}{|l|}{ Stage } \\
\hline I & 1 & & 1 & \\
\hline II & 1.00 & $1.84-4.11$ & 1.77 & $1.20-2.61$ \\
\hline III & 1.09 & 4.73-9.58 & 3.85 & $2.69-5.51$ \\
\hline IV & 4.21 & $10.1-19.6$ & 7.79 & 5.56-10.9 \\
\hline \multicolumn{5}{|c|}{ Typology of residence area } \\
\hline Predominantly urban & 1 & & - & - \\
\hline Intermediate & 0.95 & $0.83-1.09$ & - & - \\
\hline Predominantly rural & 0.85 & $0.71-1.01$ & - & - \\
\hline \multicolumn{5}{|l|}{ Period of diagnosis } \\
\hline 2000-2004 & & & 1 & \\
\hline 2005-2009 & 0.99 & $0.89-1.09$ & 0.82 & $0.74-0.91$ \\
\hline
\end{tabular}

a Each EHR is adjusted for the remaining variables.

Table 5. Adjusted EHRs stratified by stage at diagnosis.

\begin{tabular}{|c|c|c|c|c|c|c|c|c|}
\hline \multirow{2}{*}{ Variable } & \multicolumn{2}{|c|}{ Stage I } & \multicolumn{2}{|c|}{ Stage II } & \multicolumn{2}{|c|}{ Stage III } & \multicolumn{2}{|c|}{ Stage IV } \\
\hline & EHR & $95 \% \mathrm{Cl}$ & EHR & $95 \% \mathrm{Cl}$ & EHR & $95 \% \mathrm{Cl}$ & EHR & $95 \% \mathrm{Cl}$ \\
\hline \multicolumn{9}{|c|}{ Period of diagnosis } \\
\hline 2000-2004 & 1 & & 1 & & 1 & & 1 & \\
\hline 2005-2009 & 1.18 & $0.66-2.12$ & 0.63 & $0.42-0.93$ & 0.61 & $0.48-0.77$ & 0.91 & $0.80-1.03$ \\
\hline
\end{tabular}

Unfortunately, advanced stages, in particular of oral cavity and oropharynx cancers, were predominant and naturally lead to the low survival rate observed in our study. This is an important issue that must be solved in Portugal. This could be related to delays in the diagnosis of oral and oropharynx cancers [21]. A large proportion of the population does not know the early symptoms or clinical manifestations of oral cancer or are not even aware of this disease [22]. Health service interventions for head and neck cancer control 
should be implemented. Recently, a national programme to help early recognition of precancerous lesions and malignant tumours was introduced in Portugal [23]. An Early Detection Programme should involve researchers in order to better understand the biology of the disease, to find it earlier and to reduce the number of deaths caused by cancer. In addition, prevention strategies for the individual and society should also be developed. A cancer education programme should be implemented. These activities should be audited and epidemiological studies conducted to assess the results [24].

This study presents some limitations and strengths. Information on some variables was scarce especially on risk factors and some cases had no information on tumour stage and patient's outcome. We used multiple imputations to deal with the missing stage information. We grouped posterior tongue ( $\mathrm{C} 01)$ within the oral cavity according to previous studies [2] and to be able to make comparisons with others. Oropharynx cancer has been associated with HPV infection with particular characteristics including better survival than HPV negative cases $[25,26]$. Unfortunately, we do not have information on the HPV status of our tumours but it is likely that a part of these oropharynx tumours are related to HPV. We also adapted some novel methodologies. For survival determination, we used the net-survival method based on the Pohar-Perme estimator that has been described as the only unbiased estimator of net survival $[27,28]$. For comparisons among the different variables, we also used multivariable EHRs. The strengths of the study included a population-based design with almost 3,000 patients diagnosed over a decade in the north of Portugal. Our study provides information on the survival at 5 years including the trends over this ten period time and includes an analysis by clinical stage and tumour location.

\section{Conclusion}

The data presented here showed low net survival rates for oral cavity and oropharynx cancers in the north of Portugal in the time period of 2000-2009 with more than half of cases being diagnosed in advanced stages of the disease. Nevertheless, an apparent improvement in net survival from 2000-4 to 2005-9 was observed although limited to intermediate stages (II and III).

Thus, in order to increase survival at all stages, we need effective and concrete actions for population education, early diagnosis, better multidisciplinary treatment approaches, supportive care and a suitable follow-up.

\section{Acknowledgments}

We would like to thank the North Regional Cancer Registry (RORENO) of Portugal for all the support for providing the available cancer data.

\section{Funding statement}

This study had no specific funding and none of the authors received any funding related to this work.

\section{Conflicts of interest}

The authors declare that there are no potential conflicts of interest.

\section{References}

1. Ferlay J, Steliarova-Foucher E, and Lortet-Tieulent J, et al (2013) Cancer incidence and mortality patterns in Europe: estimates for 40 countries in 2012 Eur J Cancer 49(6) 1374-1403 https://doi.org/10.1016/j.ejca.2012.12.027 PMID: 23485231

2. Monteiro LS, Antunes L, and Bento MJ, et al (2013) Incidence rates and trends of lip, oral and oro-pharyngeal cancers in Portugal J Oral Pathol Med 42(4) 345-351 https://doi.org/10.1111/jop.12010 
3. Diz P, Meleti M, and Diniz-Freitas M, et al (2017) Oral and pharyngeal cancer in Europe: incidence, mortality and trends as presented to the Global Oral Cancer Forum Trans Res Oral Oncol 2 1-13

4. Albuquerque RP, Lopez-Lopez J, and Jane-Salas E, et al (2012) A pioneering epidemiological study investigating the incidence of squamous cell carcinoma of tongue in a Portuguese population Med Oral Patol Oral Cir Bucal 17 e550-e554 https://doi. org/10.4317/medoral.17746 PMID: 22322508 PMCID: 3476014

5. Monteiro L, Amaral JB, and Vizcaino JR, et al (2013) A clinical-pathological and survival study of oral squamous cell carcinomas from a population of the north of Portugal Med Oral Patol Oral Cir Bucal 19(2) e120-e126 PMID: 24121907 PMCID: 4015041

6. Warnakulasuriya S (2009) Causes of oral cancer-an appraisal of controversies Br Dent J 207 471-475 https://doi.org/10.1038/ sj.bdj.2009.1009 PMID: 19946320

7. Grégoire V, Lefebvre JL, and Licitra L, et al (2010) Squamous cell carcinoma of the head and neck: EHNS-ESMO-ESTRO Clinical Practice Guidelines for diagnosis, treatment and follow-up Ann Oncol 5 184-186 https://doi.org/10.1093/annonc/mdq185

8. World Health Organization (2007) International classification of the diseases, 10th revision [http://apps.who.int/classifications/ icd10] Date accessed: 09/01/17

9. Brandwein-Gensler M and Smith RV (2010) Prognostic indicators in head and neck oncology including the new 7th edition of the AJCC staging system Head Neck Pathol 4 53-61 https://doi.org/10.1007/s12105-010-0161-y PMID: 20237990 PMCID: 2825522

10. Instituto Nacional de Estatística, IP (2012) Censos 2011 Resultados Definitivos - Portugal (Lisbon: INE, IP) 1-560

11. Perme MP, Stare J, and Estève J (2012) On estimation in relative survival Biometrics 68(1) 113-120 https://doi.org/10.1111/j.15410420.2011.01640.x

12. Nelson CP, Lambert PC, and Squire IB, et al (2007) Flexible parametric models for relative survival, with application in coronary heart disease Stat Med 26(30) 5486-5498 https://doi.org/10.1002/sim.3064 PMID: 17893893

13. Falcaro M, Nur $\mathrm{U}$, and Rachet $\mathrm{B}$, et al (2015) Estimating excess hazard ratios and net survival when covariate data are missing: strategies for multiple imputation Epidemiology 26(3) 421-428 https://doi.org/10.1097/EDE.0000000000000283 PMID: 25774607

14. De Angelis R, Sant M, and Coleman MP, et al (2014) Cancer survival in Europe 1999-2007 by country and age: results of EUROCARE-5-a population-based study Lancet Oncol 15(1), 23-34 https://doi.org/10.1016/S1470-2045(13)70546-1

15. NIH National Cancer Institute Surveillance, epidemiology, and end results program [http://seer.cancer.gov/faststats] Date accessed: 09/01/17

16. Hakulinen T, Tryggvadóttir L, and Gislum M, et al (2010) Trends in the survival of patients diagnosed with cancers of the lip, oral cavity, and pharynx in the Nordic countries 1964-2003 followed up to the end of 2006 Acta Oncol 49(5) 561-577 https://doi. org/10.3109/02841860903575307 PMID: 20170293

17. Domínguez-Gordillo A, Esparza-Gómez G, and García-Jiménez B, et al (2016) The pattern of lip cancer occurrence over the 1990-2011 period in public hospitals in Madrid, Spain J Oral Pathol Med 45(3) 202-210 https://doi.org/10.1111/jop.12340

18. Pfister DG, Ang K, and Brockstein B, et al (2000) NCCN practice guidelines for head and neck cancers Oncology (Williston Park) 14(11A) 163-194

19. Ahn MJ, D'Cruz A, and Vermorken JB, et al (2016) Clinical recommendations for defining platinum unsuitable head and neck cancer patient populations on chemoradiotherapy: a literature review Oral Oncol 53 10-16 https://doi.org/10.1016/j.oraloncology.2015.11.019

20. Turksma AW, Braakhuis BJ, and Bloemena E, et al (2013) Immunotherapy for head and neck cancer patients: shifting the balance Immunotherapy 5(1) 49-61 https://doi.org/10.2217/imt.12.135 
21. Gómez I, Warnakulasuriya S, and Varela-Centelles PI, et al (2010) Is early diagnosis of oral cancer a feasible objective? Who is to blame for diagnostic delay? Oral Dis 16 333-342 https://doi.org/10.1111/j.1601-0825.2009.01642.x PMID: 20233328

22. Monteiro LS, Warnakulasuriya S, and Cadilhe S, et al (2016) Oral cancer awareness and knowledge among residents in the Oporto city, Portugal J Investig Clin Dent 7(3) 294-303 https://doi.org/10.1111/jicd.12158

23. Direção Geral de Saúde (2014) Norma n 002/2014 [https://www.sns.gov.pt/wp-content/uploads/2016/10/NormaN002 2014DGS.pdf] Date accessed: 09/01/16

24. Speight PM, Epstein J, and Kujan O, et al (2017) Screening for oral cancer-a perspective from the Global Oral Cancer Forum Oral Surg Oral Med Oral Pathol Oral Radiol 123(6) 680-687 https://doi.org/10.1016/j.0000.2016.08.021

25. Auluck A, Hislop G, and Bajdik C, et al (2010) Trends in oropharyngeal and oral cavity cancer incidence of human papillomavirus (HPV)-related and HPV-unrelated sites in a multicultural population: the British Columbia experience Cancer 116 2635-2644 PMID: 20336792

26. Chaturvedi AK, Engels EA, and Pfeiffer RM, et al (2011) Human papillomavirus and rising oropharyngeal cancer incidence in the United States J Clin Oncol 29 4294-4301 https://doi.org/10.1200/JCO.2011.36.4596 PMID: 21969503 PMCID: 3221528

27. Roche L, Danieli C, and Belot A, et al (2013) Cancer net survival on registry data: use of the new unbiased Pohar-Perme estimator and magnitude of the bias with the classical methods Int J Cancer 132(10) 2359-2369 https://doi.org/10.1002/ijc.27830

28. Danieli C, Remontet L, and Bossard N, et al (2012) Estimating net survival: the importance of allowing for informative censoring Stat Med 31(8) 775-786 https://doi.org/10.1002/sim.4464 PMID: 22281942 